Revista Destaques Acadêmicos, Lajeado, v. 11, n. 2, 2019. ISSN 2176-3070

DOI: http://dx.doi.org/10.22410/issn.2176-3070.v11i2a2019.2246

http://www.univates.br/revistas

\title{
O COMÉRCIO JUSTO COMO GARANTIA DE SOBREVIVÊNCIA ECONÔMICA DOS PEQUENOS PRODUTORES NO MERCADO GLOBAL
}

\author{
Joana Stelzer ${ }^{1}$, Letícia Maria da Silva ${ }^{2}$
}

\begin{abstract}
Resumo: Na qualidade de contramovimento ao Comércio Tradicional (Free Trade) temse o Comércio Justo, modalidade de troca que visa ao estabelecimento de preços justos e padrões de sustentabilidade. O objetivo geral consistiu em evidenciar o Comércio Justo como forma de garantia à sobrevivência dos pequenos produtores. Quanto aos objetivos específicos, buscou-se: descrever o cenário do crescimento e dos desafios do comércio mundial, revelar a globalização no mundo das trocas e evidenciar os princípios do Comércio Justo. Quanto aos resultados, foi possível perceber que o Comércio Justo pode mitigar as desigualdades que caracterizam o mercado global, gerando oportunidades aos pequenos produtores, em situação de exclusão e de desvantagem pelo sistema convencional de comércio. A Conclusão apontou a necessidade de permitir ao consumidor, igualmente, um comportamento responsável perante os desafios da contemporaneidade. $\mathrm{O}$ método de pesquisa adotado é o crítico indutivo, os meios de pesquisa foram exclusivamente bibliográficos. Quanto aos fins, a pesquisa apresentouse de cunho exclusivamente descritivo. Os resultados foram expostos em forma de textos.
\end{abstract}

Palavras-chave: Comércio; Globalização; Comércio Justo; Pequenos Produtores.

1 Doutora (2003) e Mestre (1998) em Direito pela Universidade Federal de Santa Catarina (UFSC). Concluiu o Pós-Doutorado (2017) pela Faculdade de Direito da Universidade de São Paulo (FADUSP). Docente credenciada no Programa de Pós-Graduação em Direito (PPGD), no Centro Ciências Jurídicas (CCJ), da UFSC. É membro da Sociedade Latinoamericana de Direito Internacional (SLADI), da Sociedade Brasileira de Direito Internacional (SBDI) e vicecoordenadora do Centro de Estudos Jurídico-Econômicos e de Gestão do Desenvolvimento (UFSC). E-mail: contatojoana@yahoo.com.br.

2 Bacharel em Direito pelo Centro Universitário de Brusque - Unifebe - Brusque/SC. PósGraduada em Direito da Aduana e do Comércio Exterior Brasileiro. Advogada. E-mail: leticia. ms9@outlook.com 


\section{INTRODUÇÃO}

No início dos tempos, os primeiros grupos de pessoas, não podiam produzir e realizar tudo o que precisavam e não existia o sistema monetário, assim, diante das necessidades que surgiam, realizavam como forma de pagamento de bens e serviços adquiridos as trocas diretas de objetos, o chamado escambo.

Com o passar dos anos, as necessidades dos seres humanos passaram a ter maior significância e o escambo não funcionava mais, necessitando de um objeto que se destacasse de outro e que permitisse a sua troca por qualquer outro produto, situação que fez surgir a moeda. Emergia, paralelamente, o espírito e o movimento do consumismo, no qual o valor da mercadoria muitas vezes não ocorria mais por necessidade, mas, pela vaidade humana.

O comércio entrou em expansão com a Revolução Industrial e o emprego de novas tecnologias fez com que a civilização ao passar dos anos ingressasse em um novo progresso: a era da globalização. Tratava-se, então, de um período de modernização econômica, cultural, jurídica e avanços tecnológicos que ligaram territórios distintos e distantes.

O processo da globalização trouxe consequências ao comércio, no sentido de interferir decisivamente na formação de preços, no processo de comercialização e principalmente pela concorrência desleal das grandes empresas que produziam em grande escala em contrapartida aos pequenos produtores. O progresso do mercado global trouxe reações injustas e não igualitárias aos pequenos produtores. Nesse momento, por volta de 1960, o Comércio Justo surgiu na qualidade de mecanismo de equilíbrio para garantir a sobrevivência desses pequenos produtores.

Sob tal contextualização, a investigação retratou o seguinte problema investigatório: Em que medida a globalização interferiu para o surgimento do Comércio Justo no cenário do comércio internacional? A hipótese aventada é que o acirramento das condições de eficiência econômica frente à sustentabilidade fizeram surgir via alternativa ao sistema de trocas. Sob tal vertente, a ideia é que o Fair Trade, com base nos seus dez princípios, viabilizou condições de equilíbrio frente às graves deficiências do comércio tradicional.

Dessa forma, o objetivo geral consistiu em evidenciar o Comércio Justo como forma de garantia à sobrevivência dos pequenos produtores familiares no mercado globalizado, vez que esses são de sensível vulnerabilidade apesar de sua importância. Os objetivos específicos que permitiram o alcance do objetivo geral foram: descrever o cenário do progresso e desafios do comércio até os dias atuais, revelar o fenômeno da globalização e seus efeitos no mundo do comércio e evidenciar o propósito e as garantias do Comércio Justo aos pequenos produtores. O estudo se justifica, pois o relacionamento do comércio internacional exige ter o ser humano como meta inarredável, mesmo quando 
propostas mais eficientes sejam apresentadas. Inverter essa fórmula significa comprometer a civilização humana.

Entre as teorias que se apresentaram para avaliar a marcha histórica das trocas internacionais e do Comércio Justo, contribuíram Antony Giddens, José Eduardo Faria, Johann Wolfgang Schneider, Joana Stelzer, entre outros.

O método utilizado foi o crítico indutivo. Os dados e as informações foram examinados sob forma qualitativa. Os meios de pesquisa foram bibliográficos, coletados por duas fontes secundárias de informação: prioritariamente, a partir de produção científica de reconhecidas obras doutrinárias; e, também, legislação internacional e pátria. Quanto aos fins, a pesquisa apresentou-se de cunho descritivo, pois pretendeu tecer uma relação fenomenológica entre comércio internacional e Comércio Justo, sem propor um novo referencial. Os resultados foram expostos exclusivamente em forma de textos.

\section{DAS ORIGENS DO COMÉRCIO À REVOLUÇÃO INDUSTRIAL}

O comércio diz respeito à compra e à venda de bens e serviços, é o ponto fundamental de encontro entre povos, culturas e países. No início dos tempos, os primeiros grupos de pessoas, não podiam produzir e realizar tudo o que precisavam, tais como roupas, utensílios, criação de animais, dentre outras. Tão pouco existia o sistema monetário, assim diante das necessidades que surgiam, realizavam como forma de pagamento de bens e serviços adquiridos as trocas diretas de objetos, o chamado escambo, quando desejavam ou necessitavam algo que não possuíam.

Lopes e Rossetti (2009) descrevem que as trocas realizadas correspondiam às necessidades limitadas à época, sendo prioridades e fundamentais produtos que se destinavam à alimentação e à proteção, que afloravam diretamente dos recursos naturais.

Os membros do grupo tendiam a desenvolver primitivos processos de conservação dos produtos extraídos da natureza, acumulando excedentes que se destinavam, em um primeiro estágio, a garantia do suprimento e, em estágio mais avançado de cultura econômica, as trocas dentro do próprio grupo ou com outros grupos com os quais passavam a manter contatos. (LOPES; ROSSETTI, 2009, p.16).

Nesse período, comerciantes levavam os seus produtos para o mercado e, por meio de trocas, adquiriam outros produtos para satisfazer as suas necessidades. Carl Menger (1983) descreve que em um primeiro momento, a troca mútua de produtos satisfazia as necessidades dos povoados uma vez que seus interesses permaneciam simplórios, apenas auferindo aquilo que realmente necessitasse, sem qualquer visão de vantagem econômica. 
Nos primórdios do comércio humano, quando, nos indivíduos, começa a despertar a consciência da vantagem econômica que podem auferir das eventuais oportunidades de permuta e os objetivos das pessoas se voltam apenas para o imediato (em decorrência da simplicidade que caracteriza toda fase inicial de um povo que desperta para a civilização), por conseguinte, cada um tem em vista tão-somente o valor de uso; ao permutar os bens, então é natural que as operações de troca se restrinjam aos casos em que os bens apresentam para os proprietários, um valor de uso menor que o de outros bens na posse de outros indivíduos com relação aos quais a escala de valores é inversa. (MENGER, 1983, p. 373)

Assim, nesse estágio, a pessoa humana buscava adquirir apenas os bens que eram - diretamente - necessários; deixando de lado o que não precisavam no final. Entretanto, à medida que as necessidades dos povos passavam a crescer e esses vinham a se fixar nos locais realizando a agricultura e a criação de animais, o escambo já não obtinha resultado, apresentando inúmeras falhas, visto que o produtor de um determinado produto deveria encontrar alguém próximo que necessitasse daquele bem e dispusesse de outro produto.

Para Menger (1983), esse âmbito das trocas de produto por produto permanecia muito restrito devido à operacionalidade, pois implicava a existência da casualidade do encontro coincidente entre dois indivíduos com escalas de valores inversos e entendidas por ambos equivalentes, trazendo uma gigante dificuldade a ser superada por tal sistema.

Ou seja, para que ocorresse essa troca de produtos, uma pessoa deveria pensar que seu produto tem menor valor do que o produto alheio e, a segunda pessoa, deveria pensar da mesma maneira, o que poderia ser raro e, mais raro ainda, seriam essas duas pessoas se encontrarem para realizar a troca. Assim passaram a adquirir bens que, inicialmente, não eram necessários para si, mas que futuramente poderiam pagar por algo que eles desejavam em algum momento adiante. Logicamente, os bens adquiridos para trocas futuras se referiam a mercadorias que eram facilmente negociadas e obtinham bastante procura no mercado.

Mas, não por muito tempo, a população diante de tal desenvolvimento e progresso das necessidades, já percebia um maior e menor grau de vendabilidade e durabilidade das mercadorias, bem como, percebiam que sob o enfoque de tais qualidades, as trocas realizadas não se davam de forma justa.

Desde então com maior significância nas necessidades do ser humano e seu desenvolvimento, um novo estágio de troca de mercadorias surgiu por intermédio do surgimento da moeda e do dinheiro, concretizando os processos de pagamento indiretos. Jozsef Robert (1982) descreve que a moeda surgiu pelo próprio desenvolvimento das necessidades de produção da população, pois necessitavam que um objeto se destacasse entre todos e que este permitisse a troca de qualquer outro produto. 
Aristóteles exemplificou que a função da moeda faz com que sua utilização atribui um determinado valor e que esse valor corresponde ao produto desejável, para que assim, haja a troca da mercadoria pela moeda de forma que ambos obtenham valores iguais. "Deste modo, agindo o dinheiro como uma medida, torna ele os bens comensuráveis e os equipara entre si; pois nem haveria associação se não houvesse troca, nem troca se não houvesse igualdade, nem igualdade se não houvesse comensurabilidade." (ARISTÓTELES, 1991, p. 108)

Superado tal progresso, emergiu na civilização nova lógica econômica em que o comerciante substituiu o valor de uso das mercadorias pelo seu valor de troca. Isso fez com que o comércio deixasse de julgar o valor das mercadorias tendo como base sua utilidade e necessidade, para calcular custos e lucros a serem convertidos em aquisições de riquezas, podendo-se dizer que estava implantado a origem do espírito e do sistema capitalista.

O espírito capitalista surgido na Baixa Idade Média Europeia veio quebrar essa longa tradição histórica. De um lado, passouse a admitir como eticamente não condenável a busca de riqueza material como finalidade última da vida. De outro lado firmou-se na nova classe burguesa a conviç̧ão de que o acúmulo pessoal de bens um poderoso instrumento de poder na sociedade. (COMPARATO, 2014, p. 54 .

Com a chegada do capitalismo, uma nova classe social se formava. A classe burguesa, detentores de capital (comerciantes, industriais, proprietários de terras, de imóveis, os possuidores de riquezas e dos meios de produção), implantou nova configuração de produção na qual se buscava o lucro e a circulação de bens em diferentes regiões por meio da produção em grande escala. Com essa nova prática, o comércio entrou em expansão, no qual o comerciante passou a trabalhar tendo como fim máximo a obtenção de lucros e acúmulos de capitais e o trabalhador passou a subordinar seu trabalho nas indústrias, em face da nova transformação mundial: a Revolução Industrial, no século XVIII.

A Revolução Industrial trouxe a intensidade da exploração da mãode-obra, o tempo começou a ser controlado por industriais e não mais pelos artesãos. $\mathrm{O}$ trabalhador perdeu o saber do produto todo ao ir trabalhar nas indústrias, já que não poderia concorrer com elas, tornaram-se, assim, subordinados às mesmas e expropriados do seu saber. (OLIVEIRA, 2019)

Karl Marx (1984) descreve que com a Revolução Industrial, a introdução da máquina expropriou o trabalho do trabalhador. 
A máquina, da qual faz parte a Revolução Industrial, substitui o trabalhador, que maneja uma única ferramenta, por um mecanismo, que opera com uma massa de ferramentas iguais ou semelhantes de uma só vez, e que é movimentada por uma única força motriz qualquer que seja sua força. (MARX, 1984, p 10).

Com a nova tecnologia de maquinário, houve o aprofundamento da divisão social do trabalho e a ampliação da exploração do trabalhador, pois houve o aumento da produtividade, criando a grande indústria. Pode-se dizer que a Revolução Industrial possibilitou a produção de produtos em larga escala, o aumento do comércio, dentre outros avanços nos quais essas mudanças aconteceram e perduraram até os dias atuais. Ademais, essa grande indústria trouxe consigo a transformação de atividades do trabalho artesanal em máquinas que incorporaram tais atividades que antes eram realizadas a mão pelos trabalhadores.

A industrialização e a urbanização provocaram enormes vertigens por força de profundas alterações nas formas de trabalho, na tecnologia, na produtividade, nas aglomerações humanas, nos meios de comunicação etc., o que abalou as estruturas sociais cristalizadas e varreu rotinas e referências estabelecidas. As mentes autoconfiantes chamavam tudo isso de "progresso", conceito que refletia melhor o entusiasmo por essas realizações do que seus efeitos perversos. (FRIDMAN, 2019)

Isso fez com que os pequenos produtores enfretassem e ainda enfrentam, situações diversas que dificultam sua produção e comercialização se comparadas à grande produção de grandes empresas movidas pelo crescimento econômico. As condições de sobrevivência desses grupos de produtores foram agravadas com a expansão tecnológica do comércio, vez que estão associados à produção de alimentos básicos, o pequeno tamanho da propriedade de terra, $\mathrm{o}$ baixo nível de renda e a não utilização de tecnologia.

\section{DA GLOBALIZAÇÃO E DE SUAS MUTAÇÕES SÓCIO-COMERCIAIS}

Superada a Revolução Industrial, após a Segunda Guerra Mundial e com a implantação do neoliberalismo, a economia do comércio mundial apreciou um longo e forte período de crescimento, marcado pela aceleração do processo da globalização. Para Antony Giddens (1991, p. 69), a globalização é a "intensificação das relações sociais em escala mundial, que ligam localidades distantes de tal maneira que acontecimentos locais são modelados por eventos que ocorrem a muitas milhas de distância, e vice-versa". Já no entendimento de José Eduardo Faria (1999, p.60) a "Globalização não é um fenômeno novo. Ele já estava presente, por exemplo, nos antigos impérios, provocando sucessivos surtos de modernização econômica, cultural e jurídica." 
Embora existam diversas controvérsias quanto ao tempo, o processo da globalização e seu real conceito, interessa nesta investigação a explanação de que com ela foram anos de um processo de reconstrução, modernização e ampliação de estruturas não somente na troca rápida de informação, mas também no advento do avanço tecnológico e das produções de mercadorias em grande escala no mundo do comércio, trazendo a aceleração na troca de bens por territórios distantes e distintos.

Nos primórdios do século XX, a Europa praticamente dominava o mundo. Os impérios europeus controlavam quase toda a África e grandes trechos da Ásia, bem como avultavam no financiamento e organização do comércio da América Latina. Esse foi o primeiro estágio da globalização, uma era de comércio global, uma era de comunicações globais por linhas telegráficas, uma era de produção e industrialização em massa - em suma, o que parecia ser uma era de progresso inevitável. (SACHS, 2005, p. 54).

Para Laski, (1982, p 97) “a necessidade de um mercado constantemente em expansão impele a burguesia a invadir todo o globo. Necessita estabelecerse em toda parte, explorar em toda parte, criar vínculos em toda a parte". Eduardo Gianetti (1999) descreve que da globalização procedem três forças poderosas.

O fenômeno da globalização resulta da conjunção de três forças poderosas: 1) a terceira revolução tecnológica (tecnologia ligada à busca, processamento, difusão e transmissão de informações; inteligência artificial; engenharia genética); 2) a formação de áreas de livre comércio e blocos econômicos integrados (como o Mercosul, a União Européia e o Nafta); 3) a crescente interligação e interdependência dos mercados físicos e financeiros, em escala planetária. (GIANNETTI, 1999, p.3).

Ainda com todo fortalecimento, avanço e desenvolvimento tecnológico das produções no comércio que causaram a integração de diferentes localidades do planeta, maior instrumentalização proporcionada pelos sistemas de comunicação e transporte que superaram as distâncias territoriais, interligando todos os povos do globo, a globalização também trouxe consigo o consumo excessivo, más distribuições de rendas, a total desvalorização dos pequenos produtores e o desrespeito ao meio ambiente visto às práticas em que se realizam as produções.

Sob a ótica de Giddens (2006, p. 24), "a globalização não se limita a empurrar para cima, também puxa para baixo". Contemporaneamente, o comércio está nas mãos de grandes empresas, deixando aos pequenos produtores, poucas oportunidades de concorrer com equidade no mercado. Santos (2000, p 10 e ss.), ao reconhecer a existência da globalização, ressalta seu 
lado perverso e danoso. A pobreza, o desemprego, a perda da qualidade de vida, o salário mínimo baixo, educação de qualidade inacessível, corrupção e outros são aspectos comuns e crescentes na realidade internacional, derivadas na lógica capitalista da competitividade do processo da globalização. (SANTOS, 2000)

Para Giddens (2006), há uma visão pessimista da globalização, em que pode ter a ideia de que em grande parte a globalização se trata de um problema do Norte industrializado, em que países em desenvolvimento do Sul têm um papel discreto ou não tem papel nenhum. Emerge, portanto, a percepção de que a globalização destrói as culturas locais, ao aumentar as desigualdades do mundo e piorar a sorte dos empobrecidos, criando um mundo de vencedores e vencidos, no qual minorias enriquecem rapidamente e a maioria vive uma vida de miséria. (GIDDENS, 2006, p. 26) Esse fato é explicado pelo conflito entre a concepção de natureza associada à produção em pequena escala e ao controle e alteração do mundo natural buscado pela lógica produtivista. (PRESS et al, 2014, p. 103-119).

Ainda, cumpre entender que com todo o processo da globalização, o indivíduo é condicionado ao consumo, criando necessidades que, na verdade, são impostas pelo progresso, pela mídia e pelo marketing, como bem destaca Santos (2003, p. 127), "consumir não mais por necessidade, mas por ansiedade".

Então, a publicidade - âncora da sociedade do consumo - baseiase em falsas ideias que vendem objetos mutáveis e consumíveis massivamente como se fossem únicos. E, na maioria das vezes, como se fossem a fórmula mágica para a realização de um sonho. (PADILHA, 2006, p 101).

Dessa forma, quase todos os elementos advindos da globalização fez com que afetassem e ainda afetam diretamente o funcionamento dos pequenos produtores em contrapartida com as grandes incorporações advindas da globalização. Os efeitos colaterais danosos da globalização em face dos pequenos produtores estão vinculados pelas grandes empresas possuírem fatores que conseguem estender a sua atividade, tais como sua liquidez financeira, ajudas governamentais (incentivos fiscais), especificidade de produção, além de o poder de influenciar consumidores.

Isso, porque a mercadoria produzida pelas grandes indústrias no mercado, além de trabalharem com diversos tipos de tecnologia, influências de publicidade e marketing, conseguem diminuir o preço dos produtos devido ao aumento da sua produção e alta procura de consumo por produtos não somente básicos, mas, também aqueles que se qualificam como supérfluos. Sob outro aspecto, os artesãos, produtores de alimentos e utensílios sem tecnologia empregada nas suas produções tem muita dificuldade em concorrer. 
O que se observa ainda é que, com a globalização, os mercados são disputados e sobrevivem apenas aqueles que possuem maior competitividade. Certamente nesse aspecto os países que dominam a tecnologia terão melhores condições de aumentar seus lucros e continuar disputando seu espaço na economia globalizada, invadindo todos os espaços globais concorrentemente ou na forma de monopólios. (ARGERICH, 2019).

Destaca-se que na comercialização está também o grande entrave da produção familiar, processo que se completa com a subordinação da produção, que passa a depender cada vez mais de insumos industriais fora do meio rural e sob controle das indústrias capitalistas. Por esse viés, diante do atual sistema capitalista e com a atuação do processo de globalização por todo o planeta, a sociedade promoveu uma mutação sobre o ato de consumir, tornando as mercadorias cada vez mais importante, não somente para aquilo que é básico na sobrevivência do ser humano, mas, também para produtos que são supérfluos.

O progresso do mercado global traz-progressivamente - reações injustas e não igualitárias aos pequenos produtores, momento no qual o mecanismo do Comércio Justo emerge como medida para garantir a sobrevivência desses pequenos produtores, enquanto movimento de justiça.

\section{FUNDAMENTOS DE COMÉRCIO JUSTO}

Sob a lógica apresentada e que caracteriza o mundo capitalista globalizado, o comércio atual é organizado visando, quase exclusivamente, à geração de lucro, sem atentar para a sustentabilidade ou aspectos inerentes à boa convivência humana. Destaca-se que os maiores beneficiários do comércio mundial estão concentrados em número de empresas multinacionais que possuem poder econômico e financeiro elevado.

Essas empresas possuem elevado poder de influência nas decisões de organizações internacionais sobre as regras que norteiam o comércio mundial, passando a exercer forte controle nos preços das mercadorias e das produções. Sob tal lógica, dificilmente um consumidor aceita preços mais elevado por determinado produto de igual qualidade. A sustentabilidade ínsita em preços maiores é - quase sempre - invisível, embora as externalidades negativas se concretizem no meio ambiente e na saúde humana.

A escalada de preços e controle (quase) monopolístico de determinados segmentos econômicos, além dos mais, reflete prática corriqueira de grandes empresas. Sob tal contexto, a produção em grande escala e a forte influência exercida sobre consumidores por meio da publicidade e marketing são o suficiente para se manterem no mercado.

Outro aspecto que merece ser destacado reside no fato de que os pequenos produtores não têm volume no giro de capital, possuindo restrições de acesso a crédito e se tornando vulneráveis frente à variação de preços. Em 
síntese, não podem se defender com produção em larga escala. Finalmente, há escassez de recursos financeiros que dificultam a aquisição de novas tecnologias.

Assim, os pequenos produtores são vulneráveis para atravessadores que compram seus produtos a preços baixos (e injustos), muitas vezes pagando menos do que o próprio custo de produzi-los, embora trazendo ao mercado a preços altos. Tal equação resulta no aumento da pobreza e na miséria dos pequenos produtores.

É neste contexto que se insere o Comércio Justo, entendido como ferramenta que procura corrigir os malefícios de um sistema comercial injusto e socialmente excludente.

\subsection{Delimitação Histórica e Conceitual}

Não há precisão ao estabelecer o ponto inicial do surgimento do Comércio Justo, contudo, registra-se que no final do século XIX, pelas mãos de algumas instituições religiosas despertou-se fenômeno que viria, futuramente, a ser conhecido como Comércio Justo. Essas instituições religiosas compravam produtos dos produtores de países pobres do Sul com a finalidade de os venderem na América do Norte e na Europa. Essas iniciativas posteriormente se expandiram de forma progressiva, especialmente pelo desequilíbrio econômico-comercial entre o Sul e o Norte Global.

Assim, o Comércio Justo ou também conhecido como Fair Trade ${ }^{3}$ apresentou-se na qualidade de movimento social e econômico internacional, criado no início do ano de 1960 na Holanda. Tratava-se, então, na promoção de determinados atores da cadeia comercial, visando denunciar injustiças no comércio tradicional (principalmente no âmbito agrícola) e estabelecer princípios e práticas comerciais cada vez mais justos e coerentes. Desse modo, iniciaram negócios entre empresas importadoras em países do Hemisfério Norte, como a Holanda, em relação aos empobrecidos e menos competitivos produtores de países do Hemisfério Sul.

A prática do Comércio Justo, ou Comércio Ético e Solidário ou Fair Trade, teve inicio em alguns países da Europa, durante a década de 1960 a partir da ação de organizações não governamentais, agências de cooperação, instituições filantrópicas e grupos de consumidores, que passaram organizar meios de comercializar os produtos dos pequenos produtores que estavam isolados comercialmente. (BB, 2019)

3 Embora exista diferença entre os dois fenômenos, as peculiaridades de cada um não serão tratadas nessa investigação. 
Para maior elucidação histórica sobre o fenômeno, cumpre elucidar que se trata-se de "um movimento social e de uma modalidade de comércio internacional que busca o estabelecimento de preços justos, bem como de padrões sociais e ambientais equilibrados nas cadeias produtivas"(COTERA; ORTIZ, 2009, p. 60).

Não se trata de uma capitulação frente ao mercado ou inversão de sistema político. O Comércio Justo não é contra o mercado e opera dentro do capitalismo.

O Comércio Justo (Fair Trade) é visto na qualidade de abordagem alternativa ao comércio tradicional (Free Trade). Trata-se de proposta escorada na parceria, oferecendo melhores condições comerciais aos que trabalham (em detrimento do comércio tradicional que coloca os trabalhadores perante os grandes compradores, que impõe preços e condições de compra). (STELZER; GONÇALVES, 2017, p. 58).

O Comércio Justo, como movimento social, surge na reação de diminuir as desigualdades que acontecem no mercado denominado Free Trade, gerando oportunidades para produtores em condições de desvantagens pelo sistema convencional de comércio. Almejam-se condições de dignidade comercial, preservando o meio-ambiente e as pessoas, sem desconsiderar o lucro.

\subsection{Princípios do Comércio Justo}

Pautando-se pela essência conceitual do Comércio Justo, as atividades de produção, transformação, distribuição, comercialização e/ou consumo dos produtos regem-se pelos seguintes princípios básicos, estabelecidos pela Organização Mundial de Comércio Justo e reproduzidos por organizações parceiras.

1 Criar oportunidades para pequenos produtores em desvantagem econômica e social, organizados democraticamente;

2 Estabelecer e manter relações comerciais solidárias, estáveis e a longo prazo, baseadas no diálogo e no respeito entre produtores, compradores e consumidores. Todos os atores comerciais envolvidos devem respeitar os princípios da democracia, transparência e prestação de contas;

3 Pagar um preço justo (combinado entre os atores de maneira dialogada, responsável e participativa, que cubra os custos de produção, uma remuneração digna do trabalho e possa ser sustentado pelo mercado) às organizações de produtores e aos produtores; uma prima social (para investimentos comunitários) e um pré-financiamento (mínimo $50 \%$ do valor do pedido final) para garantir a sustentabilidade do negócio;

4 No centro do relacionamento econômico estão os seres humanos não a maximização dos lucros; 
5 A rejeição rotunda à exploração infantil e ao trabalho forçado;

6 A não discriminação por motivo de raça, classe, nacionalidade, religião, deficiência, gênero, orientação sexual, afiliação sindical, afiliação política, HIV / AIDS, idade ou de qualquer outra índole;

7 Garantir a liberdade de associação e um ambiente de trabalho seguro e saudável para os empregados e/ou membros, assim como condições de trabalho dignas. Dignificar o trabalho;

8 Fomentar o desenvolvimento das capacidades e as habilidades, sobre tudo, dos mais desfavorecidos e mais vulneráveis: jovens, mulheres, idosos, deficientes, entre outros grupos marginados;

9 Os atores envolvidos nas relações de comércio justo também promovem ativamente os princípios e valores do comércio justo tanto a nível local como continental e internacional;

10 Praticar e defender a sustentabilidade ambiental em todos os níveis da cadeia comercial. (CLAC, 2019)

Esses princípios são fundamentais para garantir o fortalecimento da democracia; condições justas de produção, trabalho, remuneração, agregação de valor e comercialização; desenvolvimento local de forma sustentável; respeito ao meio ambiente; respeito à diversidade, garantia de equidade e não discriminação; informação ao consumidor e à integração de todos os elos da cadeia comercial.

O comércio justo procura criar os meios e oportunidades para melhorar as condições de vida e de trabalho dos produtores, especialmente os pequenos produtores desfavorecidos. A sua missão é de promover a equidade social, a proteção do ambiente e a segurança econômica através do comércio e da promoção de campanhas de conscientização. (FRETEL; SIMONCELLEBOURQUE, 2003, p. 65).

Nas palavras de Stelzer e Moreira, “almeja-se uma experiência que busca uma relação de cooperação e colaboração, nas quais devem ser privilegiados a igualdade e o respeito mútuo." (STELZER; MOREIRA, 2017, p 78). Para Mance (2019), há quatro critérios básicos de participação que caracterizam a rede de colaboração do comércio justo:

a) que nos empreendimentos não haja qualquer tipo de exploração do trabalho, por pressão política ou dominação cultural;b) que se busque preservar o equilíbrio ecológico dos ecossistemas (respeitandose, todavia, a transição de empreendimentos que ainda não sejam ecologicamente sustentáveis; c) que haja compartilhamento de significativas parcelas do excedente para expansão da própria rede; d) que se persiga a autodeterminação dos fins e a auto-gestão dos meios, em espírito de cooperação e colaboração. (MANCE, 2019). 
Sob esses elementos hermenêuticos que os princípios de Comércio Justo lançam suas bases e emergem as regras de respeitabilidade que sustentam sua rede.

\subsection{Sistemas do Comércio Justo}

O sistema Fair Trade ou Comércio Justo possui uma série de Redes de Produtores e Organizações Nacionais Fair Trade, conhecidas pela sigla como NFOs (National Fairtrade Organizations), que se ocupam em promover produtos certificados do Comércio Justo, assim como sensibilizar consumidores. Ao longo da história, o Comércio Justo teve considerável número de iniciativas por intermédio do surgimento de instituições, sob a forma de associações, entidades coordenadoras nacionais e redes colaborativas de trabalho que visam estimular o consumo ético de mercadorias. Em que pese a prática capitalista, o Comércio Justo não é contrário ao mercado, pois opera dentro do sistema. Contudo, há um esforço em trazer igualdade de oportunidade de competição aos envolvidos.

Entre as importantes organizações da rede está a World Fair Trade Organization (WFTO), criada em 1989 (antigo IFAT - International Federation for Alternative Trade). Trata-se da Federação Mundial para o Comércio Alternativo, que reúne cerca de 300 organizações em 60 países, associando produção, importação e negociação do Comércio Justo da Ásia, África, Austrália, Japão, Europa, América do Norte e América do Sul. Além dessa, cumpre citar a European Fair Trade Association (EFTA), criada em 1990, é a Federação Europeia do Comércio Justo, que desempenha o papel de facilitar o intercâmbio de informações entre seus membros e realizar de informação na Europa.

A Network of European World Shops (NEWS), por sua vez, foi criada em 1994, tratando-se de uma rede de lojas na Europa que vendem produtos do Comércio Justo, representando mais de 2.800 lojas de 15 associações nacionais de 13 países. Finalmente, cumpre destacar a Fair Trade Federation (FTF), criada em 1994, representando a Federação do Comércio Justo, correspondendo pelo nome de Organização do Comércio Alternativo da América do Norte. Trata-se de associação entre produtores, varejistas e vendedores nos Estados Unidos, favorecendo a relação entre os pequenos produtores e consumidores, educandoos sobre a importância da escolha de produtos certificados do Comércio Justo.

Na América Latina, merece destaque a Coordenadora Latino-americana e do Caribe de Pequenos Produtores e Trabalhadores do Comércio Justo (CLAC), criada em 2004, sendo uma rede que representa todas as organizações da América Latina e do Caribe que são certificadas pela marca Fairtrade ou SPP (Símbolo de Pequenos Produtores), contanto com mais de 800 organizações membros em 24 países do continente.

Com a propagação do Comércio Justo nos países, em 1997, foi criado a Fairtrade Labelling Organizations International (FLO), organismo internacional 
de certificação dos produtos que utilizam a marca Fairtrade 4 . Tal organismo é responsável por emitir o selo do Comércio Justo, sujeitando os grupos e os licenciados a inúmeras regras e procedimentos analisados e aprovados pela WFTO.

A marca Faitrade é um selo independente que aparece nos produtos finais. A certificação é uma (embora não única) forma de garantia para os consumidores de que os produtores receberam um preço que corresponde aos custos de produção. Dessa maneira, almeja-se assegurar que todos os elos da cadeia (principalmente produção) estejam em conformidade com as normas internacionais de certificação do Comércio Justo, as quais são determinadas por especialistas em certificação internacional da FLO (visando à melhoria de suas condições socioeconômicas e sempre com respeito ao meio ambiente.).

As partes envolvidas na produção e comercialização recebem inspeções anuais para garantir a transparência das transações comerciais Fairtrade, assim como para monitorar o impacto efetivo no desenvolvimento socioeconômico das comunidades beneficiadas. Destaca-se também que a importância do selo de certificação dos produtos traz maior visibilidade ao consumidor sobre a origem do produto ${ }^{5}$. A ideia da certificação consiste em marcar os produtos com o selo de certificação, oportunizando alternativa ética e responsável para todos os agentes do Comércio Justo e melhorando as condições de todos, inclusive do consumidor (afinal, não existe Comércio Justo sem consumo responsável).

A Certificação Fairtrade tem se firmado como um dos instrumentos mais bem sucedidos para a luta contra a pobreza e o acesso dos pequenos produtores ao mercado. Ao mesmo tempo, consumidores de todo o mundo reconhecem no Selo Fairtrade (e também em outros selos, como Selo SPP) a garantia de sistema verossímil e transparente na promoção do desenvolvimento sustentável.

No Brasil, em novembro de 2010, foi publicado o Decreto $n^{\circ} 7.358 / 2010$ o qual instituiu o Sistema Nacional do Comércio Justo e Solidário que, nos moldes do artigo $1^{\circ}$, possui o objetivo de, por intermédio do Ministério do Trabalho e Emprego, coordenar as ações do Governo Federal visando ao reconhecimento de práticas e promoção do Comércio Justo e Solidário. $\mathrm{O}$ artigo $2^{\circ}$ do Decreto Brasileiro $n^{\circ} 7.358 / 2010$ estabelecia:

Art. $2^{\circ}$. Para os efeitos deste Decreto, entende-se por: I - comércio justo e solidário: prática comercial diferenciada pautada nos valores de justiça social e solidariedade realizada pelos empreendimentos econômicos solidários; (BRASIL, 2019).

4 Nesse caso, a marca Fairtrade é escrita com as palavras 'fair' e 'trade' juntas. Trata-se, portanto, da marca e não do fenômeno.

5 O tema da certificação é polêmico, com discussões acirradas sobre validade e legitimidade dos denominados Selos. 
Embora esteja em vigor tal decreto, a adesão de regramentos às práticas do Comércio Justo são pouco perceptíveis no âmbito brasileiro. Após o desmantelamento da Secretaria Nacional de Economia Solidária (SENAES) e a extinção do Ministério do Trabalho, as ações de Comércio Justo foram abandonadas pelo Governo Federal. Tivesse implementado o Decreto, seria o primeiro país do mundo a implementar o Comércio Justo na qualidade de Política Pública.

\subsection{Garantias dos pequenos produtores aos consumidores}

A janela de oportunidade criada pelo Comércio Justo faz com que os pequenos produtores tenham maior participação no comércio internacional e local, freando o sistema firmado exclusivamente pela lógica do mercado competitivo e concorrente, sem ponderar as externalidades negativas que devem compor o custo de uma mercadoria. No outro lado do processo, contudo, está consumidor. Efetivamente, a sustentação do Comércio Justo está também regulada pelo reconhecimento do outro ser humano.

Assim, a certificação como produto de Fair Trade visa garantir aos pequenos produtores e trabalhadores em desvantagem, maior visibilidade frente aos consumidores e consequentemente uma remuneração justa e descente pelo seu trabalho e preços de seus produtos, independente das condições do mercado convencional.

Afinal, é importante que nessa era de globalização mundial, a sociedade seja estimulada ao consumo ético e responsável dos produtos, dando preferência aos produtos feitos por associações e cooperativas que participam do movimento de Comércio Justo e Solidário. Dito de outro modo, significa não consumir produtos que agridam o meio ambiente, dando preferência aos produtos orgânicos; pesquisar as empresas que produzem os produtos que mais se consome para saber se utilizam trabalho infantil; se têm práticas trabalhistas adequadas e se atuam de forma socialmente responsável, entre outros.

Ao adquirir produtos do Comércio Justo, o consumidor possui a credibilidade de que com a compra realizada, ele estará contribuindo efetivamente - com os princípios e fundamentos de justiça comercial, pautados na ética, sustentabilidade e igualdade, além de contribuir para a sobrevivência dos pequenos produtores na cadeia do comércio.

\section{CONSIDERAÇÕES FINAIS}

As condições de sobrevivência dos pequenos produtores no mercado global foram agravadas, seja em virtude da expansão tecnológica, da industrialização na produção de alimentos, do pequeno tamanho da propriedade de terra, do baixo nível de lucratividade, da dificuldade de acesso aos incentivos governamentais, da reduzida capacidade de convencimento do mercado consumidor, entre outros. 
O Comércio Justo, na qualidade de movimento social de reação, tem condições de mitigar as desigualdades que caracterizam o mercado global, gerando oportunidades aos pequenos produtores, em situação de exclusão e de desvantagem pelo sistema convencional de comércio.

O processo de certificação de produtos submetidos aos ditames do Comércio Justo trouxe maior visibilidade dos pequenos produtores frente aos consumidores e consequentemente viabilizaram remuneração justa e descente, independente das condições do mercado convencional. Sempre oportuno lembrar que o Comércio Justo não retrata assistencialismo, mas, tratamento justo entre comerciantes.

Pautado pelos princípios fundamentais do Comércio Justo, almejase garantir fortalecimento da democracia, condições seguras de produção, trabalho decente, remuneração suficiente para o produtor e sua família, agregação de valor, entre outros, sempre envolvido em sustentabilidade. Dito de outro modo, o Fair Trade empenha-se pelo respeito ao meio ambiente, à diversidade, à equidade e a não discriminação, sem desconhecer a informação ao consumidor e a integração de todos os elos da cadeia comercial. Ao pequeno produtor familiar, descapitalizado e desqualificado, emerge como alternativa o apoio do Comércio Justo para promover a produção familiar e sustentável em detrimento das grandes empresas.

Para tanto, o estudo revelou que o Comércio Justo no atual cenário do mercado globalizado, enraizado de injustiças e desigualdades, é a alternativa de garantia da sobrevivência dos pequenos produtores no mundo das trocas, além de permitir ao consumidor um comportamento responsável perante os desafios da contemporaneidade marcado pelo Comércio Tradicional (Free Trade), exclusor e sem garantia de sustentabilidade.

\section{REFERÊNCIAS}

ARGERICH, Eloísa Nair de Andrade. A Globalização e a Organização do Processo de Trabalho. Direito em Debate, Ano XIII no 23, jan./jun. 2005. Disponível em: http:/ / www.revistas.unijui.edu.br/index.php/revistadireitoemde bate/article/view/703/427. Acesso em: 04 abril 2019.

ARISTÓTELES. Ética a Nicômaco. Tradução de Leonel Vallandro e Gerd Bornheim. 4.ed. v. 2. São Paulo: Nova Cultural, 1991.

BB (Banco do Brasil). Loja de Sustentabilidade. Disponível em: https:/ /www.bb.com. br/portalbb /page3,8305,4948,0,0,1,6.bb. Acesso em: 5 abril 2019.

BRASIL. Dec. 7.358/2010, de 17.11.2010. Institui o Sistema Nacional de Comércio Justo e Solidário - SCJS, cria sua Comissão Gestora Nacional e dá outras providências. Disponível em: http:/ / www.planalto.gov.br/ccivil_03/_ato20072010/2010/decreto/D7358.htm. Acesso em: 07 abril 2019. 
CLAC (Coordenadora Latino-americana e do Caribe de Pequenos Produtores e Trabalhadores do Comércio Justo). Princípios básicos do Comércio Justo. Disponível em: http:/ / clac-comerciojusto.org/pt-br/comercio-justo/introduccion/principiosbasicos/. Acesso em: 5 abril 2019.

COMPARATO Fábio Konder. A civilização capitalista: para compreender o mundo em que vivemos. 2.ed. São Paulo: Saraiva, 2014.

COTERA, A; ORTIZ, H. Comércio Justo. In: A.D. CATTANI et al. (coord.), Dicionário Internacional da Outra Economia. Coimbra, Almedina. 2009.

FARIA, José Eduardo. O Direito na Economia Globalizada. São Paulo: Malheiros, 1999.

FRETEL, Alfonso Cotera; SIMONCELLE-BOURQUE, Eloise. O comércio justo e o consumo ético. Rio de Janeiro: DP\&A; Fase, 2003.

FRIDMAN, Luis Carlos. Pós-modernidade: sociedade da imagem e sociedade do conhecimento. Hist. cienc. saude-Manguinhos [online]. 1999, vol.6, n.2, pp. 353-375. ISSN 0104-5970. Disponível em: http:/ / dx.doi.org/10.1590/S0104-59701999000300007. Acesso em 01 abril 2019.

FRIEDLAND, William $\mathrm{H}$. New ways of working and organization: movements and agrifood researchers. Rural Sociology, v. 75, n. 4. 2010. Disponível em: https:/ / onlinelibrary.wiley.com/doi/epdf/10.1111/j.1549-0831.2010.00031.x. Acesso em: 05 abril 2019.

GIANNETTI, Eduardo Fonseca. Auto-Engano. São Paulo: Companhia das Letras. 1997.

GIDDENS, Anthony. O mundo na Era da Globalização. Lisboa: Editorial Presença. 6.ed. 2006.

GIDDENS, Antony. Consequências da Modernidade. Tradução de Raul Fiker. São Paulo: Unesp. 1991.

LASKI, Harold J. O manifesto comunista de Marx e Engels. Rio de Janeiro: Zahar Editores, 1982.

LOPES, João do Carmo; ROSSETTI. Economia Monetária. 9. ed. São Paulo: Editora Atlas, 2009.

MANCE, Euclides André. Redes de Colaboração Solidária. Curitiba, 2002. Disponível em: http:/ / euclidesmance.net/docs/redecolaboracao-pt.pdf. Acesso em: 5 abril 2019.

MARX, Karl. O Capital. São Paulo: Abril Cultural, 1984.. v. 1, tomo 2

MENGER, Carl. Princípios de Economia Política. Tradução de Luiz João Brauna. São Paulo: Victor Civita, 1983. 
OLIVEIRA, Elisângela Magela. Transformações no mundo do trabalho, da

Revolução Industrial aos nossos dias. Disponível em: www.seer.ufu.br/index.php/ caminhosdegeografia/article/download/15327/8626. Acesso em: 01 abril 2019.

PADILHA, Valquiria. Shopping Center - a catedral das mercadorias. São Paulo: Boitempo, 2006.

PRESS, M.; ARNOULD, E.; MURRAY, Je.B.; STRAND, K. Ideological challenges to changing strategic orientation in commodity agriculture. Journal of Marketing, v. 78, n. 6, 2014 .

ROBERT, Jozsef. A origem do dinheiro. São Paulo: Parma, 1982.

SACHS, Jeffrey. O fim da pobreza: como acabar com a miséria mundial nos próximos 20 anos. São Paulo: Companhia das Letras, 2005.

SANTOS, Laymert Garcia. Politizar as novas tecnologias: o impacto sócio-técnico da informação digital e genética. São Paulo: Ed. 34, 2003.

SANTOS, Milton. Por uma outra globalização: Do pensamento único à consciência universal. Rio de Janeiro: Record, 2000.

SCHNEIDER, Johann Wolfgang. 2010. Relatório da Pesquisa mundial de

Comércio Justo - atualização 2010. Disponível em: www.abase.org.br/downloader. php?a=0486327001400869090.pdf\&n=\%. Acesso em: 4 abril 2019.

STELZER, Joana. GONÇALVES, Everton das Neves. Transnacionalidade e Redes de colaboração Solidária: sua importância na consolidação do Comércio Justo. Revista de Estudos Constitucionais, Hermenêutica e Teoria do Direito (RECHTD), 9(1). 2017.

STELZER, Joana. MOREIRA, Alexandre Pinto. A Evolução do Comércio Justo e sua Aplicação como direito Transnacional. Revista de Direito, Globalização e Responsabilidade nas Relações de Consumo, Brasília. 2017.

ZINI, A.; ARANTES, F. Globalization: The Pros and Cons of an Unstoppable Process in Globalization. What it is and its Implications. Zini, A. (org.). Anais do Seminário 50 anos de FEA-USP,1996. 